\title{
Sentimentos vivenciados pelos profissionais de enfermagem Que atuam em unidade de emergência
}

\author{
Feelings of nursing professionals who work in emergency units
}

Sentimientos de profesionales de enfermería que trabajam en unidad de urgencia

\author{
Geraldo Magela Salomél, Maria de Fátima Moraes Salles Martins", \\ Vitória Helena Cunha Espósito"I \\ 'Hospital Geral Vila Nova Cachoeirinha. São Paulo, SP \\ "Universidade Uni Nove. São Paulo, SPP \\ "Pontifícia Universidade Católica de São Paulo. Faculdade de Educação. São Paulo, SP
}

Submissão: $07 / 08 / 2008$

Aprovação: 10/10/2009

\section{RESUMO}

Objetivo: conhecer o significado do trabalho em uma unidade de emergência para os profissionais de enfermagem. Método: tratou-se de pesquisa Qualitativa com abordagem fenomenológica. A coleta de dados foi obtida por meio de 14 entrevistas com profissionais de enfermagem. Resultados: os profissionais de enfermagem convivem com sentimentos díspares, como cansaço, esgotamento, angústia e revolta pela sobrecarga e limitações dos recursos frente às situações que envolvem risco de morte. Conclusão: apesar do estresse Que esses profissionais enfrentam durante o cotidiano de trabalho, eles mantêm o compromisso de prestar uma assistência com Qualidade e humanização, havendo tendência para exaustão emocional, desânimo e sentimentos de angústia, o Que reafirma a importância da prevenção de saúde no ambiente de trabalho.

Descritores: Enfermagem; Estresse psicológico; Saúde ocupacional.

\section{ABSTRACT}

Objective: to know the meanings fo the work in an emergency unit for nursing professionals. Method: Qualitative research with phenomenological approach. Data collection was obtained by means of 14 interviews with nursing professionals. Results: coexisting feelings of nursing professionals are fatigue, exhaustion, anguish and revolt for the work overload and resources limitations face the situations that involve death risk. Conclusion: although stress faced by nursing professionals during the daily work, they keep the commitment in assisting with euality and humanization, existing a trend for emotional exhaustion, loss of heart and feelings of anguish, what reaffirms the importance of heath prevention in work environment.

Descriptors : Nursing; Stress, psychological; Occupational health.

\section{RESUMEN}

Objetivo: conocer el significado del trabajo en una unidade de urgencia para los profesionales de enfermería. Método: se trató de una investigación cualitativa con abordaje fenomenologica. La recogida de datos fue por medio de 14 entrevistas con profesionales de enfermería. Resultados: los profesionales de enfermería tienen los sentimientos de fatiga, agotamiento, angustia y rebelión para la sobrecarga de trabajo y las limitaciones de recursos frente a las situaciones Que implican riesgo de muerte. Conclusión: a pesar del estrés Que los profesionales pasan en el dia al dia de trabajo ellos mantienen el compromiso en asistir con calida y humanización, existindo una tendencia para el agotamiento emocional, desaliento emocional y angustia lo Qué reafirma la importancia de la prevención en salud en el ambiente de trabajo.

Descriptores: Enfermería; Estrés psicológico; Salud laboral. 


\section{INTRODUÇÃO}

Abordar este tema é de extrema importância, uma vez Que os profissionais de enfermagem enfrentam circunstâncias diversas, geradoras de estresse, já Que estão em contato direto e ininterrupto com a dor, o sofrimento, a impotência, a angústia, o medo, a desesperança, a perda e a morte, podendo trazer graves conseQuências físicas, emocionais, e até mesmo, na Qualidade do cuidar.

Esses profissionais, muitas vezes, passam por privação de sono em função de extensas e múltiplas jornadas de trabalho; trabalham sob pressão; com um déficit de trabalhadores de enfermagem no serviço; com a insuficiência de recursos técnicos e materiais, a superlotação de doentes e, também, pela atuação de enfermeiros envolvidos em um fazer acelerado e rotinizado, Que prejudica a identificação e a definição das necessidades dos doentes, dos trabalhadores e do serviço, apontando para um efeito nocivo.

No processo evolutivo da profissão, a enfermagem se depara com inúmeros problemas Que estão associados às Questões históricas, à formação adQuirida, às exigências e deficiências de um sistema inserido em um determinado contexto socioeconômico e político ${ }^{(1)}$.

A enfermagem presta assistência em setores considerados desgastantes, tanto pela carga de trabalho, como pelas especificidades das tarefas, e nesse panorama, encontra-se a Unidade de Emergência (UE), Que é uma unidade apropriada para o atendimento a pacientes com afecções agudas específicas, onde existe um trabalho de equipe especializado.

Apesar dos esforços dos profissionais que trabalham nas UE, elas são vistas como ambientes frios e considerados por muitos como detentores de práticas mecanicistas. Tal opinião é fruto de relatos dos próprios pacientes. Essa visão leva-os a temer o atendimento nesse setor, embora essa unidade se destaque no contexto hospitalar, Quer em equipamentos, Quer em melhor capacitação profissional, o Que possibilita maior recuperação do paciente.

A UE não é apenas um serviço com eQuipamento especial, mas sim a prestação da assistência ao enfermo hemodinamicamente grave, como um dos fatores primordiais, Que muitas vezes chega neste setor inconsciente e acompanhado pelos familiares. Este cuidado deve ser realizado por meio de um relacionamento interpessoal, cujo instrumento se dá por via da comunicação verbal ou não verbal e o toque, contribuindo para amenizar a ansiedade e o medo do desconhecido desses enfermos.

Nesse contexto, espera-se estar oferecendo segurança, atendimento rápido e eficaz, além de um efetivo apoio emocional ao cliente e a sua família, aliados a uma atitude orientada para o aproveitamento dos recursos tecnológicos existentes.

O serviço de emergência deve tratar de pacientes graves, com risco de vida ou agravo da doença na relação tempo-dependente, no entanto, o Que vivenciamos rotineiramente é uma procura ansiosa de pacientes a esses serviços, com as mais variadas Queixas e sintomatologia, na maioria não grave, o Que tem sugerido a necessidade de avaliamos cuidadosamente os múltiplos conceitos de Serviço de Emergência ${ }^{(2)}$.

A enfermagem é a atividade de cuidar e também uma ciência cuja essência e especificidade são o cuidado ao ser humano de modo integral e holístico, desenvolvendo de forma autônoma ou em equipe atividades de promoção e proteção da saúde e prevenção e recuperação de doenças.

O cuidar, e o cuidado do ser só existem sob a égide de uma ampla compreensão da vida. É preciso saber por Que cuidamos, para então estabelecer o como cuidamos. Fala ainda Que cuidar é "remédio" para a vida de Quem cuida e para a vida de Quem é cuidado, e é um "remédio" Que nasce da nossa essência humana, é universal ${ }^{(3)}$.

O profissional de enfermagem tem como agente de trabalho o homem, e, como sujeito de ação, o próprio homem. Há uma estreita ligação entre o trabalho e o trabalhador, com a vivência direta e ininterrupta do processo de dor, morte, sofrimento, desespero, incompreensão, irritabilidade e tantos outros sentimentos e reações desencadeadas pelo processo doença ${ }^{(4)}$.

A enfermagem tem um compromisso, como papel definidor, Que é o cuidar, cuidar de si, cuidar do outro, cuidar da vida, está na origem da existência é inerente ao ser humano; é um modo de ser sempre presente, essencial, é base da existência; nossas ações rotineiras, cotidianas demonstram nossa preocupação e zelo pela vida $^{(5)}$. A enfermagem também é a arte e a ciência do cuidar, do cuidar de pessoas. Para Que isso seja viável, é necessário um processo de interação entre Quem cuida e Quem é cuidado; é necessário Que haja troca de informações e de sentimentos entre essas pessoas $^{(6)}$. O ato de cuidar na enfermagem estabelece uma relação muito próxima, muitas vezes íntima, de contato físico intenso e permeado por várias sensações e sentimentos. Essa atuação diretamente sobre o corpo do outro faz com Que o profissional ou aluno de enfermagem entre em contato com a intimidade do cliente. Sendo assim, a enfermagem deve superar temores Que contribuirão para sua plena humanização, abastecendo-se com toda a carga dos mais nobres sentimentos, em especial, o amor e o amar, a solidariedade, a compaixão, fazendo do atendimento de enfermagem em algo especial, verdadeiro, indispensável ${ }^{(1)}$.

Como a UE é um ambiente estressante, não se pode descuidar da equipe. Para a equipe executar uma assistência dentro dos valores éticos, além do conhecimento das técnicas e da tecnologia utilizada no setor, a instituição deve também reconhecer Que o profissional é um ser humano e investir na sua capacitação, reconhecendo o seu potencial e limitações. Assim, estará fornecendo um suporte para Que a profissão seja executada com humanidade. O profissional irá, então, reconhecer a sua aparente insensibilidade Que, na realidade, não deixa de ser uma máscara, Que faz com Que ele se configure como herói do cuidado. Sendo herói, não poderá mostrar o Quanto ele é sensível. O cuidador só poderá prestar uma assistência humanizada por meio da sua própria humanização e da sua valorização como ser humano(8).

Sendo, a profissão de enfermagem a arte de cuidar do outro, é importante Que este profissional procure manter seu corpo e a mente saudável, através do lazer, do esporte, da boa alimentação e evitando o estresse. Pois o cuidado só acontece Quando há uma troca de sentimentos.

É necessário Que as instituições tenham um espaço destinado ao apoio psicológico para os funcionários e, Que esta ofereça a oportunidade necessária para discutir Questões conflitantes, sofrimentos e propor sugestões. Acreditamos que o profissional respeitado e valorizado desempenha melhor sua atividade, com conseQüente melhoria na Qualidade da assistência prestada ao paciente $^{(9)}$. 
Quando a instituição olha para o cuidador nessa dimensão, o ato de humanizar estará transcendendo seu significado etimológico e representando muito mais do Que simplesmente tocar, olhar, ouvir, dialogar, fornecer treinamento ou fazer um procedimento de enfermagem. Quando se fala em humanização do funcionário, significa, na verdade, fornecer condições dignas de trabalho, valorizá-lo, respeitá-lo. Assim, o profissional terá condições psicológicas e físicas de prestar uma assistência com Qualidade e humanizada.

Ao vivenciar e praticar essas ações no nosso cotidiano, estamos desenvolvendo uma assistência dentro dos valores éticos da nossa profissão. Os outros profissionais, e até mesmo a sociedade, valorizam e reconhecem a enfermagem como elemento essencial e necessário ao cuidado do outro.

Então, diante a circunstâncias diversas vivenciadas, Qual é o sentimento destes profissionais de enfermagem durante o seu plantão na unidade de emergência?

Sendo assim, o objetivo do presente estudo foi compreender como os profissionais de enfermagem se sentem trabalhando em uma unidade de emergência, visto Que esta é considerada como um ambiente estressante, proporcionando-lhes um momento de reflexão sobre o significado destes.

\section{REFERENCIAL TEÓRICO}

A palavra fenomenologia foi usada pela primeira vez, em $1764^{(10)}$ e foi compreendida como teoria da aparência, visão falsa da realidade. Em 1804, Fichte usou a fenomenologia num sentido diferente de Lambert, porém mantendo a idéia de teoria da aparência Que, para ele era a manifestação de algo real, verdadeiro, uma revelação. Com Hegel, Que se dedicou ao estudo do movimento do espírito, a fenomenologia definiu-se como método e filosofia.

No entanto, foi no início do nosso século que a fenomenologia afirmou-se como uma linha de pensamento, com Edmund Husserl, (1859-1938), na Alemanha, o Qual utilizou o nome de fenomenologia, imprimindo-lhe um novo significado: método de apreender e dizer os fenômenos Que se referem à realidade, Que se manifesta por si mesma.

A esse respeito, comenta Husserl[1 ${ }^{(1)}$, "(...) não é das filosofias Que deve partir o impulso da investigação, mas sim das coisas e dos problemas (...)".

Em síntese, a filosofia de Husserl nasceu ainda como reação ao idealismo racionalista, divergindo de suas construções a priori, e ao positivismo, já Que esse considera válido apenas os fenômenos empiricamente pesquisados. Assim, o filósofo em Questão define a fenomenologia como "ciência dos fenômenos", sendo fenômeno compreendido como o Que é imediatamente dado em si mesmo à consciência. O lema "voltar às coisas mesmas" é uma tentativa de aproximação às coisas, sem preconceitos ou pressupostos interpretativos $^{(10)}$.

A fenomenologia preocupa-se com a essência do fenômeno a partir da experiência vivida e sua investigação é um interrogar a coisa mesma. Fenômeno é entendido como aquilo Que surge para uma consciência, como resultado de uma interrogação ${ }^{(12)}$.

Etimologicamente, o termo fenômeno procede do grego phainomenon e significa um discurso esclarecedor a respeito daQuilo Que se mostra para o sujeito interrogador. Origina-se do verbo phainesthai, Que significa trazer à luz, no sentido de desvelar. Fenômeno é, então, tudo o Que se mostra, se manifesta, se desvela ao sujeito Que o interroga.

Assim, a fenomenologia proposta por Husserl, já relatada anteriormente, busca uma volta ao mundo da experiência, "ao mundo vivido", com a preocupação de compreender o fenômeno a partir de suas descrições e não de explicações, não se atendo a buscar relações causais. $\mathrm{O}$ direcionamento é no sentido de mostrar e não de demonstrar. A fenomenologia emprega necessariamente uma forma de reflexão, Que deve incluir a possibilidade de olhar as coisas e como elas se manifestam. A perspectiva de voltar às coisas mesmas direciona a uma essência, o Que significa Que não se pode reduzi-las a sua única dimensão de fato. A essência permite identificar perspectivas do fenômeno, porQue ela é sempre idêntica a si própria, não importando a circunstância da sua realização ${ }^{10)}$.

Enfocando a assistência de enfermagem numa visão fenomenológica, Boemer ${ }^{(12)}$, resgata a percepção do homem como um ser com um horizonte de possibilidades. Compreende Que, para resgatar a totalidade do homem, é preciso romper com a visão de homem fragmento - soma das partes e relações causais entre as manifestações das doenças - tratando-se de uma ruptura do discurso comum no cotidiano hospitalar.

Compreendeu-se que assumir algumas idéias básicas da investigação fenomenológica na enfermagem é adotar, essencialmente, uma postura Que envolve voltar-se para o outro, enQuanto pessoa em sua própria experiência de vida, enquanto sujeito ativo, com múltiplas possibilidades de existir, um vir a ser.

\section{MÉTODO}

Esta pesquisa foi de natureza Qualitativa, buscando fundamentação fenomenológica, visto Que permitiu desvelar, mostrar e apreender os sentimentos dos profissionais de enfermagem que trabalham em unidade de emergência diante das situações estressantes vivenciadas durante o turno de trabalho.

A pesquisa foi realizada numa UE de um hospital geral e estadual de grande porte, localizado na região norte da cidade de São Paulo. A escolha desta instituição deu-se ao fato de ser o local da realização de algunss dos estágios curriculares da graduação, Quando foram iniciadas as primeiras observações em relação ao fenômeno interrogado.

A sala de emergência conta com seis leitos e, atuam nesse setor médicos, enfermeiros, auxiliares de enfermagem, totalizando dezesseis profissionais para Quatro turnos de trabalho.

A proposta foi a de entrevistar enfermeiros e auxiliares de enfermagem, de ambos os sexos, Que trabalham na sala de emergência, e Que tivessem no mínimo um ano de experiência no setor.

O convite para participar da pesquisa foi feito previamente e, após aceitação dos profissionais, as entrevistas foram agendadas e realizadas na própria unidade, com a preocupação de não interferir na rotina do setor, assegurando a privacidade dos sujeitos da pesquisa. Os dados foram coletados após aprovação do projeto pelo Comitê de Ética em Pesquisa da Universidade Uni Nove, sob o número: 171637/08 e assinatura do Termo de Consentimento Livre e Esclarecido pelos participantes da pesquisa. Os sujeitos foram informados a respeito da proposta e da importância da pesquisa, receberam explicações sobre a forma de coletar as entrevistas, o 
anonimato e sobre a possibilidade de se desvincularem da pesquisa, bem como a obtenção do Termo de Consentimento Livre e Esclarecido, conforme Resolução Federal no 196/96, do Conselho Nacional de Saúde, do Ministério da Saúde, Que respaldou todo o estudo. Após os participantes terem assinado o Termo de Consentimento Livre e Esclarecido, iniciamos as entrevistas. Os participantes da pesquisa foram identificados com algarismos romanos.

As entrevistas foram agendadas e realizadas na unidade de emergência entre abril e maio de 2008, a partir de uma pergunta aberta, tendo como Questão norteadora: "Como você se sente trabalhando em uma unidade de emergência"?

Os diálogos foram gravados e posteriormente transcritos para captar com fidedignidade as respostas obtidas com a anuência dos participantes, de acordo com a Questão norteadora.

A saturação dos dados (discursos) ocorreu ao totalizar 14 entrevistas, o Que, fenomenologicamente, significa Que se chegou à parte da estrutura do fenômeno, à parte de sua essência, uma vez Que o alcance da essência total não é possível.

A análise compreensiva dos relatos implicou um momento de intersubjetividade, de encontro de nosso pensar como pesquisadores e do pensar dos sujeitos participantes, o Que possibilitou explicitar diferentes facetas apreendidas nas descrições.

A análise das descrições foi realizada, tendo como referencial a proposta de Espósito(13).

A leitura de cada entrevista foi iniciada, procurando familiarização com o todo, sempre tentando apreender o mundo do entrevistado, atentando para sua fala, incluindo aspectos da linguagem verbal e não-verbal.

Posteriormente, retornou-se aos discursos, agora mais atentamente, focalizando a temática estudada, para captar as unidades de significados, isto é, os aspectos essenciais do fenômeno Que se mostraram significativos. Iniciamos a análise dos dados por meio da redução fenomenológica. Assim, desconsiderou-se tudo o Que não dizia respeito ao fenômeno, mantendo as proposições significativas. Chegou-se às unidades de significados, numerando-as uma a uma e, assim, obtivemos uma visão global do discurso. A seguir, cada unidade de significados foi reescrita na busca da clareza do discurso, procurando expressar o pensamento articulado (redução).

Esse procedimento foi realizado para todos os discursos dos sujeitos. Em seguida, buscou-se as convergências das unidades de significados em cada um deles; as unidades foram, então, agrupadas com a finalidade de organizar as articulações do discurso, formando núcleos de pensamentos Que foram sintetizados e tematizados conforme várias perspectivas Que emergiram das experiências dos profissionais de enfermagem. A tematização surgiu do agrupamento das unidades de significados, evidenciando-se, assim, duas categorias temáticas: "vivenciando momento de desgaste emocional durante o período de trabalho" e "métodos para aliviar o estresse".

\section{RESULTADOS}

\section{O desgaste emocional durante o período de trabalho}

A partir dos discursos dos profissionais de enfermagem, observouse que nos aproximamos do seu mundo vivido. Suas falas expressam Que convivem com sentimentos díspares: o cansaço, o esgotamento, a angústia, impotência e dores devido à sobrecarga de trabalho, provocada pela falta de material, de profissionais. Mesmo diante a estas circunstâncias eles procuram prestar uma assistência de Qualidade. Assim, esses profissionais ficam expostos ao risco de desenvolverem o estresse ocupacional. Esses riscos variam de acordo com o trabalho realizado, o tipo de instituição, setor onde a pessoa trabalha, recursos humanos, equipamentos disponíveis e outras características, de acordo com a organização do trabalho e a estrutura do ambiente $\mathrm{e}^{(14)}$.

A exposição prolongada e contínua ao estresse pode desenvolver seu processo insidioso. Além disso, as atividades dos profissionais de enfermagem sejam assistenciais ou administrativas exigem elevado grau de agilidade, destreza física e energia.

Em estudos realizados por Costa et $\mathrm{al}^{(15)}$, concluiu-se que o trabalho, Quando realizado em condições insalubres e inseguras, tem influência direta sobre o bem-estar físico e psíquico da pessoa. E, segundo Almeida e Pires ${ }^{(16)}$, os trabalhadores sentem-se impotentes e desgastados perante uma demanda de trabalho superior às capacidades de resposta da equipe.

Na dimensão exaustão emocional, o indivíduo sente-se esgotado e com a sensação de Que não será possível recuperar sua energia, torna-se irritável e amargo, pouco generoso, sente-se menos capacitado a cuidar dos outros e torna-se pessimista. A partir desse Quadro, poderá sobrevir uma despersonalização nesse profissional, traduzida pelo distanciamento emocional e indiferença diante do sofrimento alheio, com uma perda da capacidade de empatia, o Que faz com Que o paciente seja tratado como um objeto ${ }^{(17)}$.

Os relatos a seguir evidenciam essa situação:

"Quando estou sozinha no plantão fico muito cansada e estressada durante e após o plantão, pelo motivo Que estamos com o número de funcionários reduzido na UE e além de ser enfermeiro assistencial, tenho de realizar o serviço administrativo". Discurso I.

“O plantão na UE é geralmente estressante, principalmente porque durante a noite, os pacientes não são evoluídos e acabo fazendo toda sistematização dos pacientes e o pior que eu tenho de colher todos os exames de rotina". Discurso VII.

Alguns autores ressaltam a complexidade existente nas UE, revelando à importância de se rever as Questões Que permeiam o relacionamento interpessoal da equipe de enfermagem nesse contexto, tendo em vista os problemas emergentes de circunstância em Que as peculiaridades do ambiente ocasionam aos seus profissionais, e também evidencia o nível de ansiedade e tensão provocado, sobretudo, pela elevada responsabilidade que a enfermagem enfrenta em seu cotidiano profissional ${ }^{(18)}$.

Em trabalho realizado por Rocha et al ${ }^{(19)}$, concluiu-se que as causas de adoecimento podem ser fatores internos ao trabalho, como as más condições de trabalho, (ambientes, instrumentos e equipamentos, trabalho pesado, repetitivo, sobrecarga) e fatores da vida pessoal (doenças crônicas, dupla jornada, problemas familiares e falta de recursos financeiros). A exposição e essa variedade e intensidade de cargas gera processo de desgaste no corpo biopsíquico do trabalhador Que varia desde indisposições passageiras a doenças instaladas, no conjunto ou em específico.

“Cuidar de vários pacientes com poucos funcionários deixa a 
gente estressada mesmo. $O$ pior Que entre esses auxiliares são poucos Que são bons profissionais, interessados. A gente tem Que ficar de olho nele. QualQuer ser humano fica estressado e sem ânimo para o trabalho nesse setor. Se pelos menos a gente fosse valorizado, recebesse elogios". Discurso X

Quanto aos itens sentir-se desvalorizados, ter subordinados pouco competentes e sentir-se só para tomar decisões, a implementação de atividades de educação permanente com a equipe de enfermagem, abordando temas específicos da profissão, Que necessitam de maior aprofundamento, humanização nas relações de trabalho, estudos de casos que contribuam na tomada de decisão e elevação da auto-estima, dentre outros, poderão concorrer para melhor enfrentamento de situações estressantes ${ }^{(20)}$.

Essas situações, relacionadas à falta de recursos humanos suficientes para a prestação da assistência rotineira e emergencial aos pacientes fazem com Que aumente o sofrimento mental e físico do profissional. Assim, compete-lhes tomar decisões delicadas que mobilizam forte carga afetiva, uma vez Que convivem com a angústia dos pacientes e familiares. Cabe-lhes ainda dar suporte ao paciente e família, além de fazer adaptações radicais no processo de trabalho, Quase sempre sob condições bastante precárias.

Apesar da tensão emocional constante e da vontade de desistir, visto Que os problemas presentes no cotidiano lhes parecem maiores do Que os recursos disponíveis para resolvê-los, os profissionais de enfermagem têm satisfação em trabalhar na unidade de emergência, desfrutam da sensação de dever cumprido, conseguem salvar vidas, sobrepondo-se às dificuldades por eles encontradas. Essas perspectivas foram expressas nas falas abaixo:

"Apesar do estresse, eu gosto muito de trabalhar neste setor, pois estou ajudando esses pacientes que estão precisando de ajuda, auxílio. Se o hospital oferecesse melhores condições, o meu serviço seria melhor". Discurso XIII

“(...) AQui neste hospital a gente tem oportunidade de crescer profissionalmente, a chefia apóia a gente, mas o problema é Que não temos funcionários suficientes para trabalhar; muitas vezes eu sou enfermeiro assistencial e administrativo. No final do plantão eu estou muita cansada e sem ânimo para nada. Mas o importante é que através do meu serviço, estou ajudando as outras pessoas doentes, Que são os pacientes de Quem estou cuidando". Discurso IX

Percebe-se Que a maioria dos profissionais sente-se gratificada em cuidar de pacientes, porém vivenciam angústias intensas, estresses pelo fato de terem de realizar grande número de procedimentos complexos.

Estudo de relatos de profissionais mostrou Que eles são benevolentes e atenciosos para com os pacientes. Apesar do sistema desgastante e da carga de sofrimento psíquico, conseguem manter e expressar suas emoções, ou seja, reafirmar o compromisso de oferecer afeto, cordialidade e trabalho humanizado ${ }^{(21)}$.

É possível perceber, por meio da análise dos depoimentos, Que a exposição dos trabalhadores às inúmeras modalidades e intensidade de risco, intermediada pela falta de funcionários, matérias, desvalorização do profissional e outros fatores pode desencadear insatisfação, apatia pelo trabalho e doenças ocupacionais.

Os trabalhadores de enfermagem submetem-se constantemente às condições inadequadas, originando agravos no seu sistema corporal de origem psíeuica, oportunizando os acidentes do trabalho Que levam às licenças para tratamento ${ }^{(22)}$.

Os principais fatores de risco discutidos pelos autores relacionam-se à (des)organização do trabalho e aos fatores ambientais e ergonômicos inadequados. Dentre eles, a movimentação e o transporte de pacientes; a postura corporal inadeeuada, o déficit de pessoal, os equipamentos inadequados e sem manutenção são os mais enumerados pelos trabalhadores ${ }^{(20}$.

Tais fatos podem ser observados nas falas abaixo:

"Por muitas vezes sinto que vou perder o rumo/caminho da melhor resolução problema, sentindo-me impotente e fragilizado, fico tão nervosa Que as minhas pernas e braços após o plantão doem muito". Discurso IV

"O estresse é tanto, que quando termina o plantão sinto que todo o meu corpo dói. Dói demais na região lombar e cervical. Não tenho vontade de sair de casa e de passear". Discurso VIII

As Queixas relacionadas ao aparelho osteomuscular representam uma das maiores causas de sofrimento nos trabalhadores de enfermagem, sendo Que esses agravos assumem proporções maiores entre as mulheres trabalhadoras, fator Que se justifica não somente pela fragilidade biológica inerente à mulher, mas em especial pela sua inserção no mundo do trabalho ${ }^{(22)}$.

A análise dos diversos estudos mostrou não só uma elevada ocorrência de distúrbios musculoesqueléticos em trabalhadores de enfermagem (80\% a 93\%), mas também Que tais distúrbios atingem principalmente a região lombar, os ombros, os joelhos e a região cervical $^{(23)}$.

"Muitas vezes na hora em Que estou prestando cuidados (fazendo o exame físico, evoluindo o paciente, curativo e outros procedimentos) os pacientes ficam falando e se queixando de sua vida. Só sei que eu fico ouvindo, dando a atenção necessária porque eu estou ali para fazer o meu procedimento com um toque de humanização e também dar a atenção a ele. Muitas vezes não dá tempo de fazer algum serviço burocrático. Não dar conta de todo serviço me deixa cansada e com muitas frustrações". Discurso II

Os profissionais de enfermagem Que desenvolvem atividades de assistência à saúde na comunidade, pela característica do tipo de trabalho, a proximidade com a clientela e sua realidade, seus problemas e limitações, estão expostos a fontes diversas de estresse e outras doenças ocupacionais, ficando, portanto, mais vulneráveis a agravos de saúde ${ }^{(14,24)}$.

“Uma coisa que deixa a gente muita estressada é Quando a gente esta cuidando de um paciente muito grave e ele vem a falecer". Discurso XIV

"As universidades deveriam ter também incluído na grade curricular programa anti estresse com o objetivo de preparar e ensinar os 


\section{alunos a enfrentar esse mal do século XXI". Discurso VI}

Acreditamos Que todas as profissões Que lidam diariamente com o público em geral, Que estão em perigo de morte, sejam altamente estressantes e desgastantes para o individuo. Entre as profissões, podemos destacar aquelas Que possuem um alto grau de contatos interpessoais, como os profissionais de enfermagem ${ }^{(22)}$.

"Como a enfermagem é uma profissão estressante e muitas vezes cansativa pelo acúmulo de serviço, no meu pensar, acho que os presidentes do COREN e COFEN deveriam unir-se mais aos sindicados para obrigar os hospitais a elaborarem medidas $e$ ações anti estresse." Discurso XI

"É de extrema relevância a identificação de estratégias no trabalho para o controle do estresse, a fim de trazer benefícios para ambos, profissionais e comunidade assistida." Discurso XII

Em seu estudo, Elias e Navarro ${ }^{(22)}$, ressaltaram a importância de se implantar programa de apoio à pesquisa sobre estresse acadêmico. Pontuaram a necessidade de a comunidade acadêmica monitorar-se, fornecer apoio aos seus componentes, sendo imprescindíveis ações Que minimizem fatores de estresse.

Como o setor de UE é um ambiente estressante, não se pode descuidar da equipe. Para a equipe executar uma assistência dentro dos valores éticos, além do conhecimento das técnicas e da tecnologia utilizada no setor, a instituição deve também reconhecer Que o profissional é um ser humano e investir na sua capacitação, reconhecendo o seu potencial e limitações. Assim, estará fornecendo um suporte para Que a profissão seja executada com humanidade. O profissional irá, então, reconhecer a sua aparente insensibilidade Que, na realidade, não deixa de ser uma máscara, Que faz com Que ele se configure como herói do cuidado. Sendo herói, não poderá mostrar o Quanto ele é sensível. O cuidador só poderá prestar uma assistência humanizada por meio da sua própria humanização e da sua valorização como ser humano.

Quando a instituição olha para o cuidador nessa dimensão, o ato de humanizar estará transcendendo seu significado etimológico e representando muito mais do Que simplesmente tocar, olhar, ouvir, dialogar, fornecer treinamento ou fazer um procedimento de enfermagem. Quando se fala em humanização do funcionário, significa, na verdade, fornecer condições dignas de trabalho, valorizá-lo, respeitá-lo. Assim, o profissional terá condições psicológicas e físicas de prestar uma assistência com Qualidade e humanizada.

\section{Métodos para aliviar o estresse}

Nas últimas décadas muitos indivíduos estão procurando a cura, melhora ou alivio do estresse através das terapias ditas alternativas. Fazendo com Que as terapias alternativas ganhem espaço no processo pela busca da cura, em Que se evidencia o olhar holístico sobre o homem, percebendo-o como um conjunto de corpo, alma e psiQue.

Tais fatos podem verificar nas falas abaixo:

"Deste que comecei a tomar Floral de Bach, eu não fico mais muito estressada, cansada como antes eu ficava." Discurso VI "Quando eu passei no médico, ele falou Que eu estava estressada, então ele prescreveu Floral de Bach."

\section{(...) só sei de uma coisa, é Que eu melhorei muito com esses} remédios." Discurso XIII

Pesquisa realizada por Souza et $\mathrm{al}^{(25)}$, concluiu Que $64 \%$ dos indivíduos perceberam alterações nas emoções ou comportamento após a administração de florais, passando de sensação de estresse e angústia para calma, traneüilidade, leveza.

"Muitas vezes Quando o plantão era estressante eu sentia dores no corpo, cansaço, depois Que comecei a tomar florais, e fazer sessão de Reiki essas dores melhorou muito. Não fico cansada mais". Discurso III

As terapias alternativas tem beneficio na redução da dor e do estresse das pessoas, no estímulo e socialização das emoções ${ }^{(26)}$.

Em trabalho realizado por Salomé(27), concluiu Que o Reiki produz relaxamento, emocional e mental, reduzindo rapidamente Quadro de estresse, melhorando a depressão, ansiedade e diminuindo dores. Porém ele sugere novos estudos com um número maior de amostra, a fim de possibilitar a visualização da bioenergia como matéria a ser tratada academicamente.

"Só sei de uma coisa, Quando eu saio de um plantão, muito estressante, eu chego em casa tomo um banho bem Quente, deito no sofá eu ouço uma música suave. Sei que sinto leve e relaxada." Discurso I

A música, de forma particular e opcional torna-se uma alternativa criativa para minimizar provavelmente os efeitos da monotonia e da intolerância, permitindo ao individuo mergulhar no seu íntimo e usufruir o prazer de ouvir música. Também pode levar para a mente e o corpo os recursos interiores do espírito, podendo ser associada com os tratamentos terapêuticos ortodoxos ${ }^{(28)}$.

\section{CONSIDERAÇÕES FINAIS}

Os resultados deste estudo demonstraram Que os profissionais de enfermagem vivenciam momentos de estresse, cansaço, esgotamento e frustração no seu cotidiano de trabalho. Os fatores Que geram esses sentimentos são: acúmulo de funções, atividades burocráticas e assistenciais e as limitações do tempo para executarem as tarefas assistenciais e burocráticas.

Eles usam como métodos para aliviar tais alterações físicas e as frustrações a música, Reiki, e Florais de Bach. Utilizando tais Terapias alternativas eles estão trilhando caminhos, criando oportunidades para alcançar o bem estar e saúde com ações criativas, menos diretivas e mais humanizadas.

Diante do exposto, faz-se necessário rever tais situações e desenvolver mecanismos Que reestruturem a prática da enfermagem com vistas a melhores condições de trabalho e diminuição dos efeitos deletérios à saúde desses profissionais. Também se torna importante a realização de novos estudos, Que visem diagnosticar fatores de risco para a saúde desses profissionais, para Que se criem estratégias de enfrentamento do cotidiano laboral Que possam levar à prevenção contra doenças relacionadas ao trabalho nesses 
indivíduos.

Enfim, enQuanto enfermeiro Que se interessa pela saúde do trabalhador, acreditamos ser importante levar esses dados aqui apreendidos ao conhecimento dos diretores de enfermagem e administradores hospitalares, como proposta de princípio de reflexão.

A tarefa da reflexão é tentar colocar, de modo claro, as estruturas do existir dos trabalhadores de enfermagem que, muitas vezes, no seu período de trabalho, correm o risco de doenças ocupacionais (estresse e Síndrome de Burnout) Que, com algumas medidas adequadas, poderiam ter sua incidência diminuída. Assim como captar a sua significação, para, então, como diria Heidegger, "abrir horizontes". É necessária a conscientização dos diretores de enfermagem e administradores hospitalares Quanto à importância da formação de equipes multi e interdisciplinares, as Quais poderão discutir sobre os fatores de riscos Que os profissionais estão vivendo no seu cotidiano de trabalho e também realizar planos de medidas e intervenções anti-estresse. Há Que se insistir: o estresse, além de prejudicar a vida do trabalhador com Queda da sua auto-estima e da auto-imagem, faz com Que a assistência prestada não tenha excelência de Qualidade e a necessária humanização.

\section{REFERÊNCIAS}

I. Carvalho MVB. O cuidar de enfermagem hoje: uma arte Que se renova, uma ciência Que se humaniza. Rev Téc Cient Enferm. 2003; I (6): 435-42.

2. Gattl MFZ, Leão ER. O papel diferenciado do enfermeiro em serviço de emergência: a identificação de prioridade de atendimento. Rev Nursing 2004; 73(7): 24-9.

3. Bittes |A. O cuidar, a ciência do ser humano unitário e o budismo nitiren: união entre ciência e religião. Rev Téc Cient Enferm 2003; I (5): 37I-5.

4. Batista KM, Bianchi ERF. Estresse do enfermeiro em unidade de emergência. Rev Latino-am Enfermagem 2006; I 4(4): 534-9.

5. Urasaki MBM. A interconexão da sensibilidade e da razão no cuidar. Rev Paul Enferm 200 I; 20(2): 4-11.

6. Lemos RCA, Rossi LA. O significado cultural atribuído ao centro de Terapia Intensiva por clientes e seus familiares: um elo entre a beira do abismo e a liberdade. Rev Latino-am Enfermagem 2002; 10(3): 345-57.

7. Lima RC, Brêtas JBS. Estudo comparativo entre séries de graduação em enfermagem: representações dos cuidados ao corpo do cliente. Acta Paul Enferm 2006; 19(4): 379-86.

8. Salomé GM. A face oculta dos profissionais de enfermagem Que trabalham em uma unidade de terapia intensiva [dissertação]. São Paulo: Universidade Federal de São Paulo; 2007.

9. Silva GF, Sanches PG, Carvalho MDB. Refletindo sobre o cuidado de enfermagem em unidade de terapia intensiva. Rev Mineira Enferm 2007; I I (1): 94-8.

10. Capalbo C. Alternativa metodológica de pesquisa. In: $3^{\circ}$ Seminário Nacional de Pesquisa em Enfermagem. 1984; Florianópolis (SC) Brasil. Florianópolis: ABEn-SC; 1984. p. 130.

I I. Husserl E. A filosofia como ciência do rigor. Coimbra: Atlântida. 1962

12. Boemer MR. A condução de estudos segundo a metodologia investigação fenomenológica. Rev Latino-am Enfermagem 1996 ; 2(1): 83-94.

13. Espósito VHC. Conhecimento e Interdisciplinaridade. In: Furtado AG, Bastazin V, organizadores. Literatura infantil e juvenil: uma proposta interdisciplinar. São Paulo: Editora do Autor; 2007. p. $175-218$

14. Camilo SHH, Angerami ELS. O estresse e o profissional Que atua na assistência à comunidade: uma revisão da literatura.
Rev Nursing 2006; 97(8): 855-9.

15. Costa IRA, Lima IV, Almeida PC. Stress no trabalho do enfermeiro. Rev Esc Enferm USP 2003; 37(3): 63-71.

16. Almeida PIS, Pires DEP. O trabalho em emergência: entre o prazer e o sofrimento. Rev Eletrônica Enferm 2007; 9(3): 617-29.

17. Glasberg J, Horiuti L, Novais MAB, Canavezzi AZ, Chicoli FA. Prevalence of the burnout syyndrome among Brazilian medical oncologists. Rev Assoc Med Bras 2007; 53(I): 85-9.

18. Ferrareze MVG, Ferreira V, Carvalho AP. Percepção do estresse entre enfermeiro Que atuam em terapia intensiva. Acta Paul Enferm 2006; 19(3): 310-5.

19. Rocha AM, Godoy SCB, Carvalho LP, Souza M|B. Percepção gerencial sobre o adoecimento dos trabalhadores de um serviço hospitalar de nutrição. Rev Mineira Enferm 2007; 1 I (I): 53-60.

20. Montanholi LL, Tavares DMS, Oliveira GR. Estresse: fatores de risco no trabalho de enfermeiro hospitalar. Rev Bras Enferm 2006; 59(5): 661-5.

21. Amestoy SC, Schwartz E, Thofehrn B. A humanização do trabalho para os profissionais de enfermagem. Acta Paul Enferm 2006; 19(4): 444-9.

22. Elias MA, Navarro VL. A relação entre o trabalho, a saúde e as condições de vida: negatividade e positividade no trabalho das profissionais de enfermagem de um hospital escola. Rev Latinoam Enfermagem 2006; 14(4): 517-25.

23. Mognago TSBS, Lisboa MTL, Souza MTL, Moreira MC Distúrbios músculo-esqueléticos em trabalhadores de enfermagem: associação com condições de trabalho. Rev Bras Enferm 2007; 60(6): 70 I-5.

24. Salomé GM, Espósito VHC, Silva GTR. The nursing professional in an Intensive Therapy Unit. Acta Paul Enferm 2008; 2 I(2): 294- 99.

25. Souza ABG, Confuorto A, Oliveira S. O uso do floral rescue remedy em grupo de estudantes sob estresse. Rev Enferm Brasil 2003; 2(3): 150-4.

26. Gimenez CS, Reiners AAO. Terapias alternativas: um estudo bibliográfico. Rev Nursing 2007; 10(1 I0): 324-8.

27. Salomé GM. A influência do reiki no equilíbrio físico e emocional dos profissionais de enfermagem. Rev Nursing 2005; 8 (83): 179 184.

28. Giannotti LA, Pizzoli LML. Musicoterapia na dor: diferenças entre os estilos jazz e new age. Rev Nursing 2007; 7(71): 35-41. 